\title{
LABA/LAMA fixed-dose combinations in patients with COPD: a systematic review
}

This article was published in the following Dove Press journal:

International journal of COPD

\author{
Paola Rogliani' \\ Luigino Calzetta' \\ Fulvio Braido ${ }^{2}$ \\ Mario Cazzola' \\ Enrico Clini ${ }^{3}$ \\ Girolamo Pelaia ${ }^{4}$ \\ Andrea Rossi ${ }^{5}$ \\ Nicola Scichilone ${ }^{6}$ \\ Fabiano Di Marco ${ }^{7}$ \\ 'Department of Experimental \\ Medicine and Surgery, University \\ of Rome Tor Vergata, Rome, Italy; \\ ${ }^{2}$ Department of Internal Medicine, \\ IRCCS San Martino Genoa University \\ Hospital, Genoa, Italy; ${ }^{3}$ Department \\ of Medical and Surgical Sciences, \\ University of Modena and Reggio \\ Emilia, Modena, Italy; ${ }^{4}$ Department \\ of Medical and Surgical Sciences, \\ Section of Respiratory Diseases, \\ Magna Græcia University, Catanzaro, \\ Italy; ${ }^{5}$ Pulmonary Unit, University of \\ Verona, Verona, Italy; ${ }^{6}$ Department \\ of Internal Medicine, University of \\ Palermo, Palermo, Italy; ${ }^{7}$ Department \\ of Health Sciences, Università \\ degli Studi di Milano, Respiratory \\ Unit, Papa Giovanni XXIII Hospital, \\ Bergamo, Italy
}

Correspondence: Paola Rogliani Department of Experimental Medicine and Surgery, University of Rome Tor Vergata, Via Montpellier I, Rome 00133 , Italy

Tel +390620904656

Email paola.rogliani@uniroma2.it
Objectives: The aim of this study was to assess the current evidence for long-acting $\beta_{2}$-agonist (LABA)/long-acting muscarinic antagonist (LAMA) fixed-dose combinations (FDCs) in the treatment of COPD.

Materials and methods: A systematic literature search of randomized controlled trials published in English up to September 2017 of LABA/LAMA FDCs vs LABA or LAMA or LABA/ inhaled corticosteroid (ICS) FDCs in COPD patients was performed using PubMed, Embase, Scopus, and Google Scholar. Outcomes including forced expiratory volume in 1 second $\left(\mathrm{FEV}_{1}\right)$, Transition Dyspnea Index (TDI) scores, St George's Respiratory Questionnaire (SGRQ) scores, exacerbations, exercise tolerance (endurance time [ET]), inspiratory capacity (IC), and rescue medication use were evaluated.

Results: In total, 27 studies were included in the review. LABA/LAMA FDCs significantly improved lung function $\left(\mathrm{FEV}_{1}\right)$ at 12 weeks compared with LABA or LAMA or LABA/ICS. These effects were maintained over time. Significant improvements with LABA/LAMA FDCs vs each evaluated comparator were also observed in TDI and SGRQ scores, even if significant differences between different LABA/LAMA FDCs were detected. Only the LABA/LAMA FDC indacaterol/glycopyrronium has shown superiority vs LAMA and LABA/ICS for reducing exacerbation rates, while olodaterol/tiotropium and indacaterol/glycopyrronium have been shown to improve ET and IC vs the active comparators. Rescue medication use was significantly reduced by LABA/LAMA FDCs vs the evaluated comparators. LABA/LAMA FDCs were safe, with no increase in the risk of adverse events with LABA/LAMA FDCs vs the monocomponents.

Conclusion: Evidence supporting the efficacy of LABA/LAMA FDCs for COPD is heterogeneous, particularly for TDI and SGRQ scores, exacerbation rates, ET, and IC. So far, indacaterol/ glycopyrronium is the LABA/LAMA FDC that has the strongest evidence for superiority vs LABA, LAMA, and LABA/ICS FDCs across the evaluated outcomes. LABA/LAMA FDCs were safe; however, more data should be collected in a real-world setting to confirm their safety.

Keywords: LABA, LAMA, fixed-dose combination, COPD, systematic review

\section{Introduction}

COPD is a chronic disease characterized by not fully reversible, commonly progressive airflow limitation. According to the WHO estimates, 65 million people have moderateto-severe COPD worldwide. In 2005, COPD-related deaths accounted for 5\% of worldwide deaths; the data certainly underestimated as the most epidemiological data that originate exclusively from high-income countries. ${ }^{1}$ Based on current figures, WHO predicts a 30\% increase in COPD deaths over the next 10 years, which will make COPD the third highest cause of death worldwide by $2030 .{ }^{1}$

Guidelines and recommendations aim at assisting physicians during the process of diagnosis and disease management so that any single COPD patient may receive 
the most appropriate medical care by adhering to evidencebased medicine. Bronchodilators are the mainstay of COPD treatment. Long-acting $\beta_{2}$-agonists (LABAs) or ultra-LABAs and long-acting muscarinic antagonists (LAMAs) are the preferred options for patients at different stages of the disease. Indeed, the most recent update of the Global Initiative for Chronic Obstructive Lung Disease (GOLD) recommendations states that 1) LABAs and LAMAs significantly improve lung function and dyspnea health status, and reduce exacerbation rates, and 2) combination treatment with LABA/LAMA increases forced expiratory volume in 1 second $\left(\mathrm{FEV}_{1}\right)$ and reduce COPD symptoms compared with monotherapy. ${ }^{2}$ Both statements are provided with the highest strength of recommendation according to the level of evidence (level A). ${ }^{2}$ Benefits of LABA/LAMA fixed-dose combinations (FDCs) are widely reported; ${ }^{3-5}$ however, the availability of different FDC options approved for the treatment of COPD and the absence of head-to-head studies between all the available LABA/LAMA FDCs make choosing the most appropriate option difficult.

Therapeutic choice always depends on the evaluation of biological characteristics of the disease, symptoms, previous therapies and responses to them, health status, and last but not least patient preference. Therefore, the optimal therapy is the one drawn on the medical history of each patient. However, results from clinical trials, clinical practice, and guidelines are essential for an evidence-based medicine approach.

Patients' characteristics such as age, cognitive status, visual acuity, manual dexterity, manual strength, and coordination may influence the correct use of inhaler devices and, thus, the efficacy of inhaled medications. In fact, for several patients using a nebulizer, a pressurized metered dose inhaler or a dry powder inhaler device provides an easy-to-use and cost-effective therapy. ${ }^{6}$

This review will systematically and critically examine the available evidence on marketed LABA/LAMA FDCs or those under development in terms of clinical relevance for the management of COPD.

\section{Materials and methods}

\section{Review questions}

Is the evidence for the efficacy of LABA/LAMA FDCs for COPD the same across the literature?

Are the numbers of randomized controlled trials (RCTs) on LABA/LAMA FDCs and their clinical relevance the same across the literature?

\section{Search strategy}

This systematic review has been registered in PROSPERO (registration number: CRD42017070930; https://www.crd. york.ac.uk/prospero/display_record.php?RecordID $=70930$ ) and performed in agreement with the Preferred Reporting Items for Systematic Reviews and Meta-Analyses (PRISMA) statement (Figure 1). ${ }^{7}$ This systematic review satisfied all the recommended items reported by the PRISMA-P 2015 checklist. ${ }^{8}$

We undertook a comprehensive literature search for RCTs published in English and looking at the impact of LABA/ LAMA FDCs in patients with COPD. The search was performed in PubMed, Embase, Scopus, and Google Scholar through to September 2017, in order to provide for relevant studies available up to September 30, 2017.

The terms "aclidinium," "formoterol," "glycopyrronium," "glycopyrrolate," "indacaterol," "olodaterol," "salmeterol," "tiotropium," "umeclidinium," and "vilanterol" were searched for the FDCs, and the term "chronic obstructive pulmonary disease" OR "COPD" was searched for the disease.

Studies reporting the impact of the currently approved doses (European Medicines Agency and/or the United States Food and Drug Administration dosing) of LABA/LAMA FDCs vs LABAs or LAMAs or LABA/inhaled corticosteroid (ICS) FDCs on lung function (trough and peak FEV ) $^{\text {) dysp- }}$ nea (assessed using Transition Dyspnea Index [TDI] scores), quality of life (assessed using St George's Respiratory Questionnaire [SGRQ] scores), COPD exacerbation rates, exercise tolerance (assessed by endurance time [ET]), inspiratory capacity (IC), and the use of rescue medication were included in this systematic review. Two reviewers independently checked the relevant studies identified from literature searches and databases. The studies were selected in agreement with the previously mentioned criteria, and any difference in opinion about eligibility was resolved by consensus.

\section{Quality score}

The Jadad score, with a scale of 1-5 (score of 5 being the best quality), was used to assess the quality of studies concerning the likelihood of biases related to randomization, double blinding, withdrawals, and dropouts. ${ }^{9}$ Studies were considered of high quality if they had a Jadad score $\geq 3$. Two reviewers independently assessed the quality of individual studies, and any difference in opinion about the quality score was resolved by consensus.

The quality of the publications was assessed in agreement with the Grading of Recommendations Assessment, Development, and Evaluation (GRADE) system. ${ }^{10}$ 


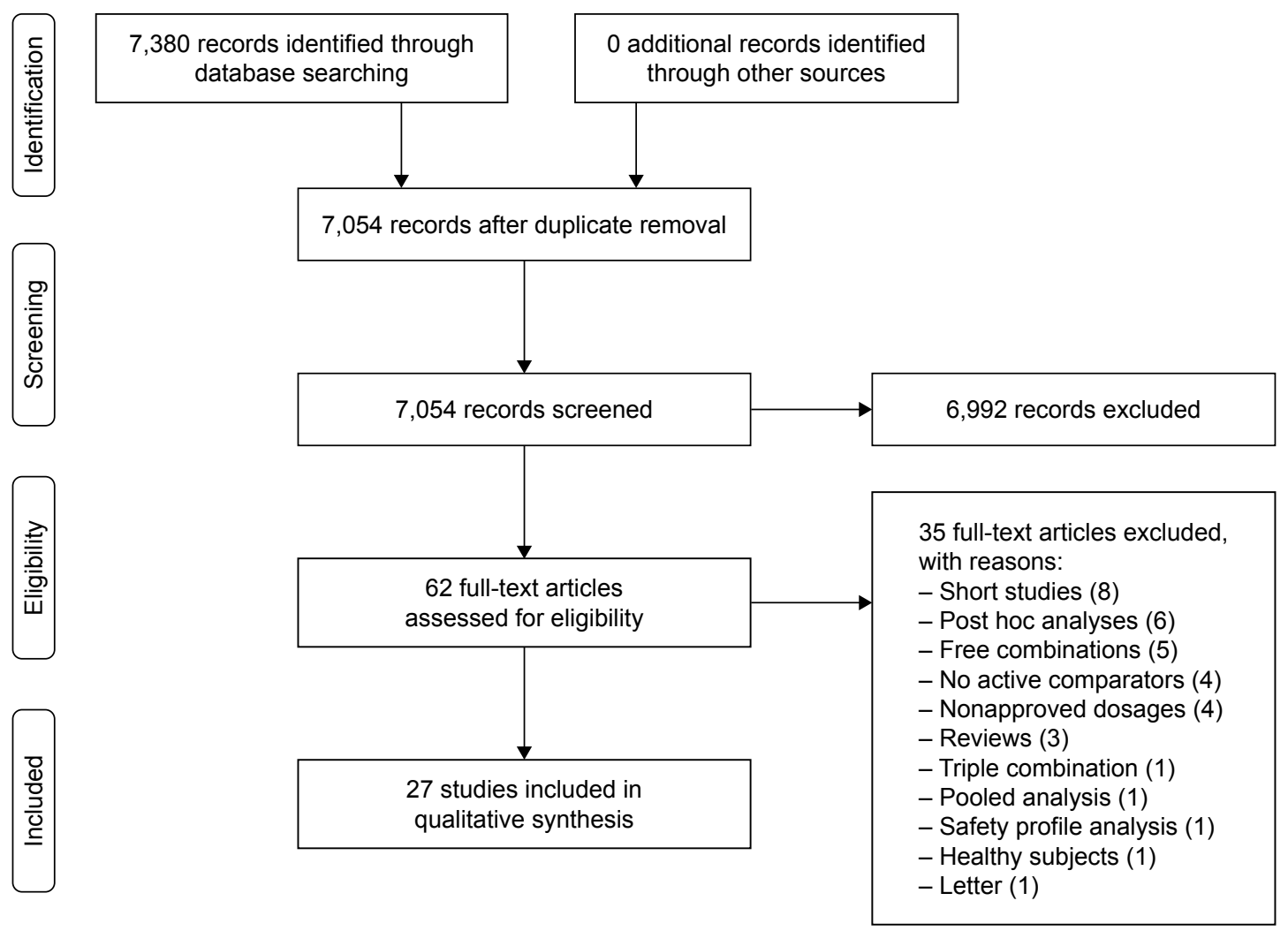

Figure I PRISMA flow diagram for the identification of studies included in the systematic review concerning the impact of LABA/LAMA FDCs in COPD. Abbreviations: FDCs, fixed-dose combinations; LABA, long-acting $\beta_{2}$-agonist; LAMA, long-acting muscarinic antagonist; PRISMA, the Preferred Reporting Items for Systematic Reviews and Meta-Analyses.

\section{Data extraction}

Data from included studies were extracted and checked for study references, RCT registry number, study duration, doses

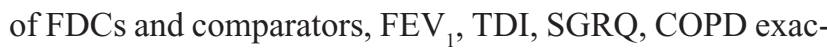
erbations, ET, IC, rescue medication, and Jadad score.

\section{End points}

The primary objective of this systematic review was to assess the impact of LABA/LAMA FDCs vs comparators on FEV TDI and SGRQ (treatment duration $\geq 12$ weeks; statistically significant improvement vs comparators), COPD exacerbations (treatment duration $\geq 52$ weeks; statistically significant reduction of moderate-severe exacerbation rate and/or risk vs comparators and/or statistically significant increase of the time to the first exacerbation; exacerbations have been evaluated when included among the outcomes of RCTs and not if reported as adverse events [AEs]), ET and IC (treatment duration $\geq 3$ weeks; statistically significant improvement vs comparators), and rescue medication (treatment duration $\geq 12$ weeks; statistically significant reduction of puff/ day vs comparators). The secondary objective was to assess the safety profile of LABA/LAMA FDCs vs comparators.

\section{Strategy for data synthesis}

A systematic narrative synthesis was performed on the results of the included studies (Table 1), ${ }^{11-37}$ structured around the type of intervention, target population characteristics, type of outcome, and intervention content. The superiority of LABA/ LAMA FDCs vs comparators was reported and discussed in agreement with the abovementioned criteria.

\section{Results}

Of the 62 potentially relevant studies identified in the initial search, 27 (44\%) studies were deemed eligible for a qualitative analysis (Figure 1); their characteristics are summarized in Table 1. All the clinical trials were high-quality studies with a Jadad score $\geq 3$. Patients enrolled in the selected clinical trials had to be able to correctly use the inhaler devices. Furthermore, the overall comorbidities were comparable among the studies. Table 2 shows the synthesis of the main pharmacological characteristics of LABAs, LAMAs, and ICS in the clinical trials included in this systematic review. Table 3 summarizes the studies in which LABA/ LAMA combinations were significantly superior, similar, or inferior to comparators. 


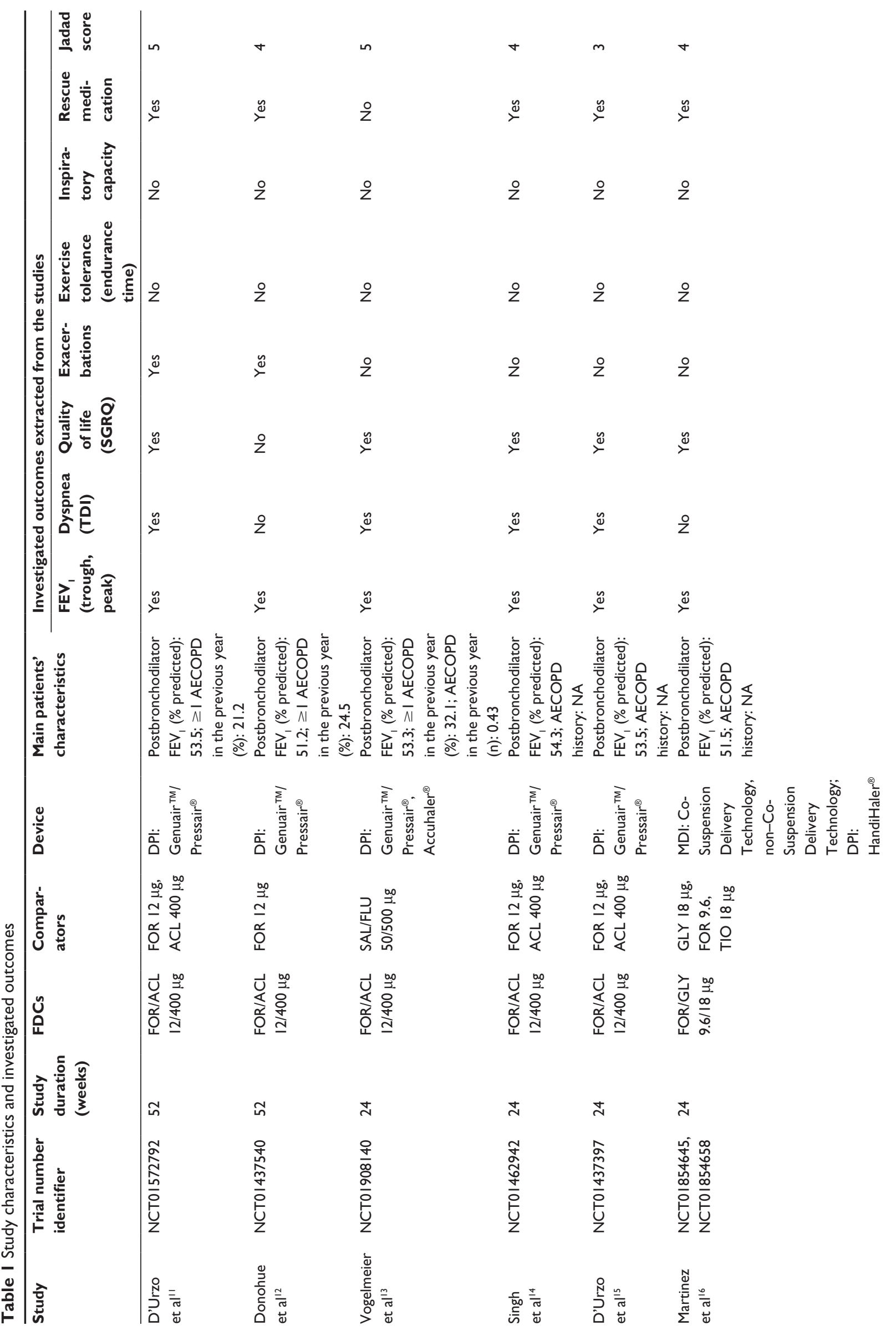




\begin{tabular}{|c|c|c|c|c|}
\hline$\nabla$ & $m$ & $\sigma$ & in & in \\
\hline 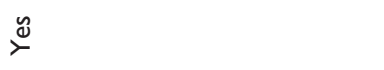 & $\stackrel{\tilde{\nu}}{\check{\nu}}$ & $\stackrel{\check{\nu}}{\check{\nu}}$ & $\stackrel{\check{\nu}}{\check{\nu}}$ & $\stackrel{\check{\Xi}}{\check{\nu}}$ \\
\hline$\stackrel{\circ}{z}$ & 우 & 으 & 으 & 으 \\
\hline$\stackrel{\circ}{z}$ & 으 & 으 & 으 & 으 \\
\hline$\stackrel{y}{\nu}^{y}$ & zo & $\stackrel{\ddot{y}}{\succ}$ & $\stackrel{y}{\nu}$ & ㅇ \\
\hline$\stackrel{\nu}{\nu}^{\ddot{x}}$ & zo & zo & $\stackrel{\ddot{\Perp}}{\nu}$ & $\stackrel{\ddot{\nu}}{\nu}$ \\
\hline$\stackrel{y}{\check{\nu}}$ & $\stackrel{\mathscr{y}}{\succ}$ & 우 & 으 & $\stackrel{\mathscr{y}}{\succ}$ \\
\hline$\stackrel{y}{\check{\nu}}$ & $\stackrel{\mathscr{y}}{\succ}$ & $\stackrel{y}{\check{\nu}}$ & $\stackrel{\mathscr{y}}{\succ}$ & $\stackrel{\mathscr{y}}{\succ}$ \\
\hline 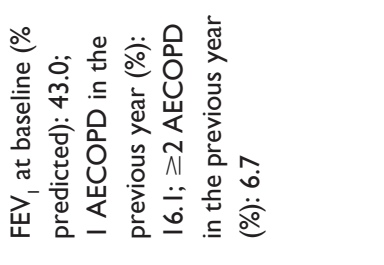 & 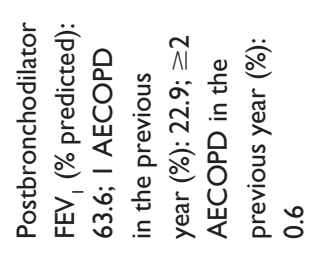 & 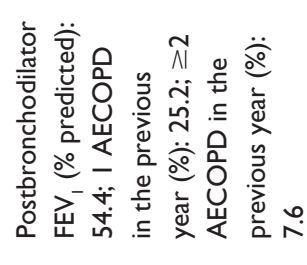 & 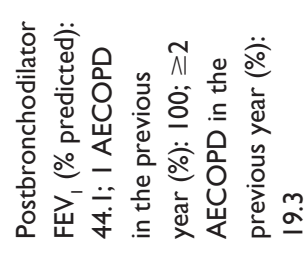 & 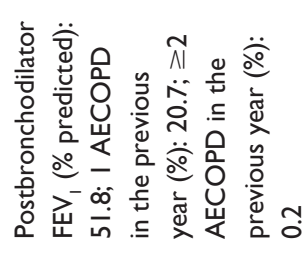 \\
\hline 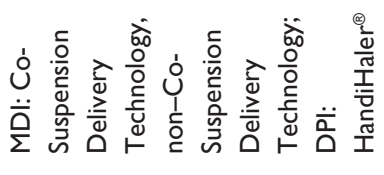 & & 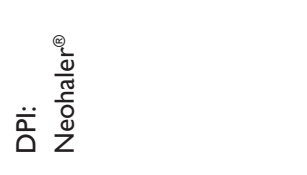 & 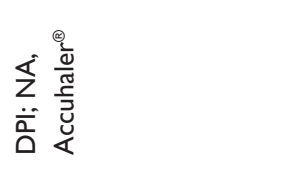 & 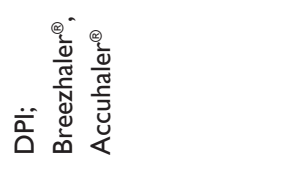 \\
\hline 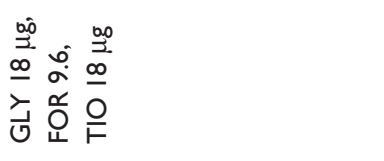 & 离 & $\begin{array}{l}\frac{00}{2} \\
\stackrel{n}{n} \\
\underline{a}\end{array}$ & 至 & 党总 \\
\hline 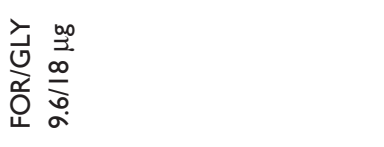 & 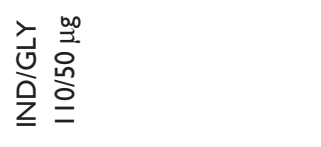 & 光 & 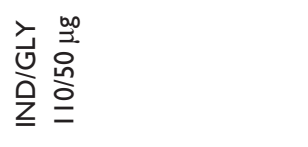 & 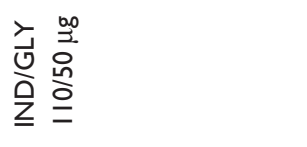 \\
\hline ก & $\simeq$ & ก & กี & $\stackrel{\sim}{ }$ \\
\hline 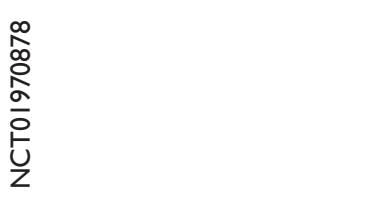 & 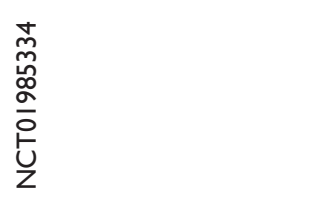 & 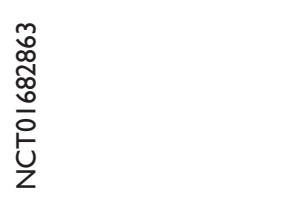 & 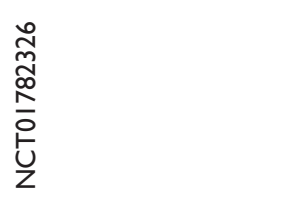 & $\begin{array}{l}\text { ò } \\
\text { ồ } \\
\frac{0}{0} \\
\frac{0}{2} \\
z\end{array}$ \\
\hline 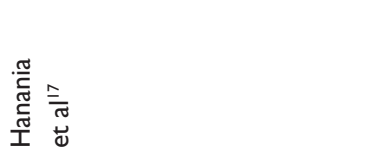 & 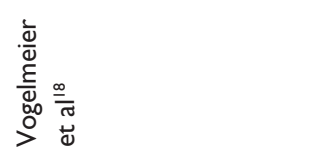 & 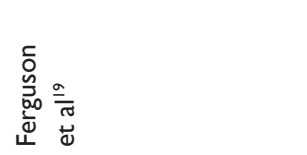 & 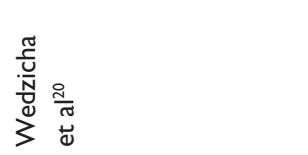 & 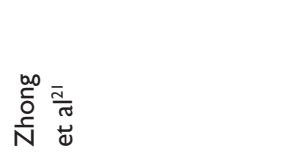 \\
\hline
\end{tabular}




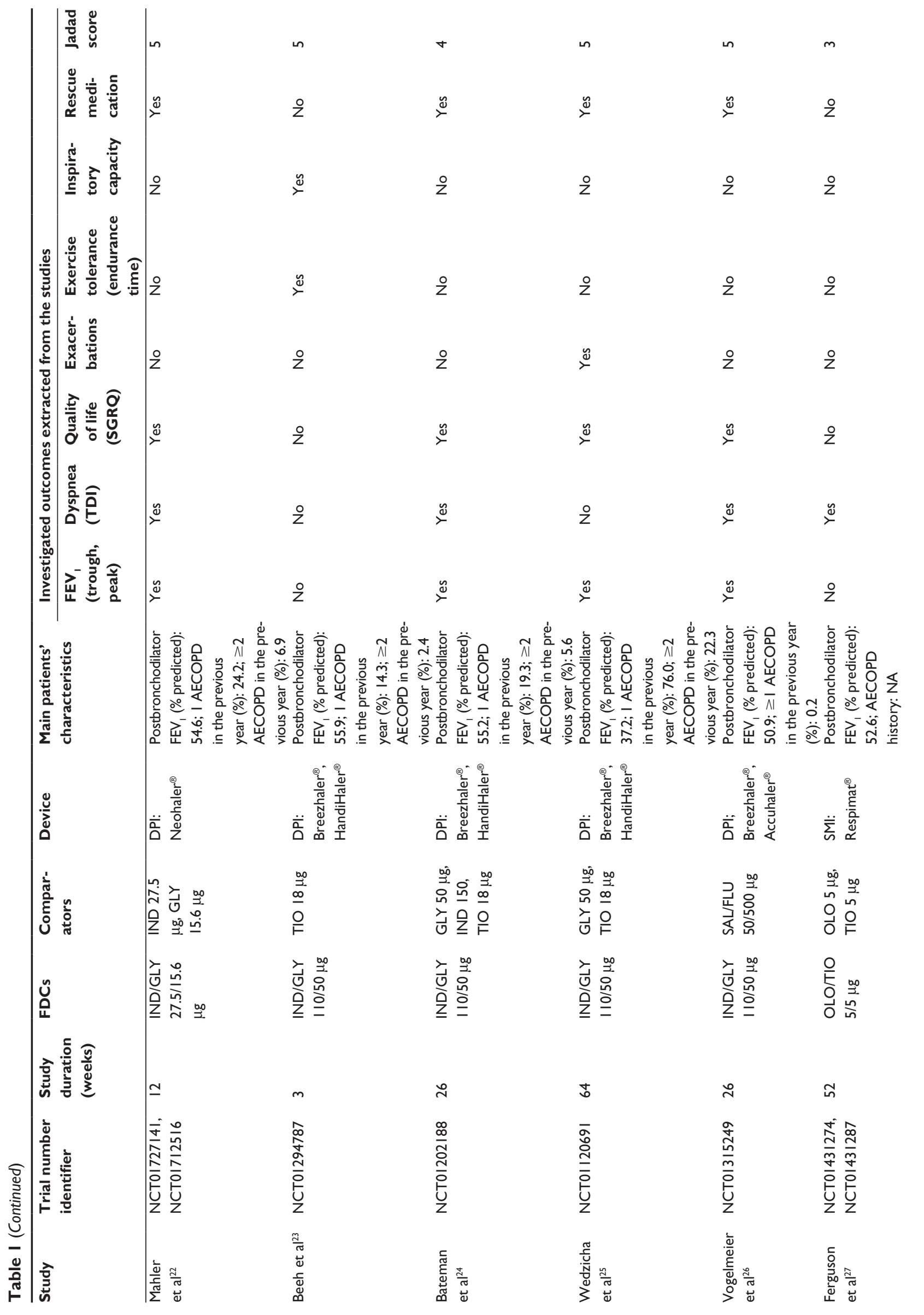




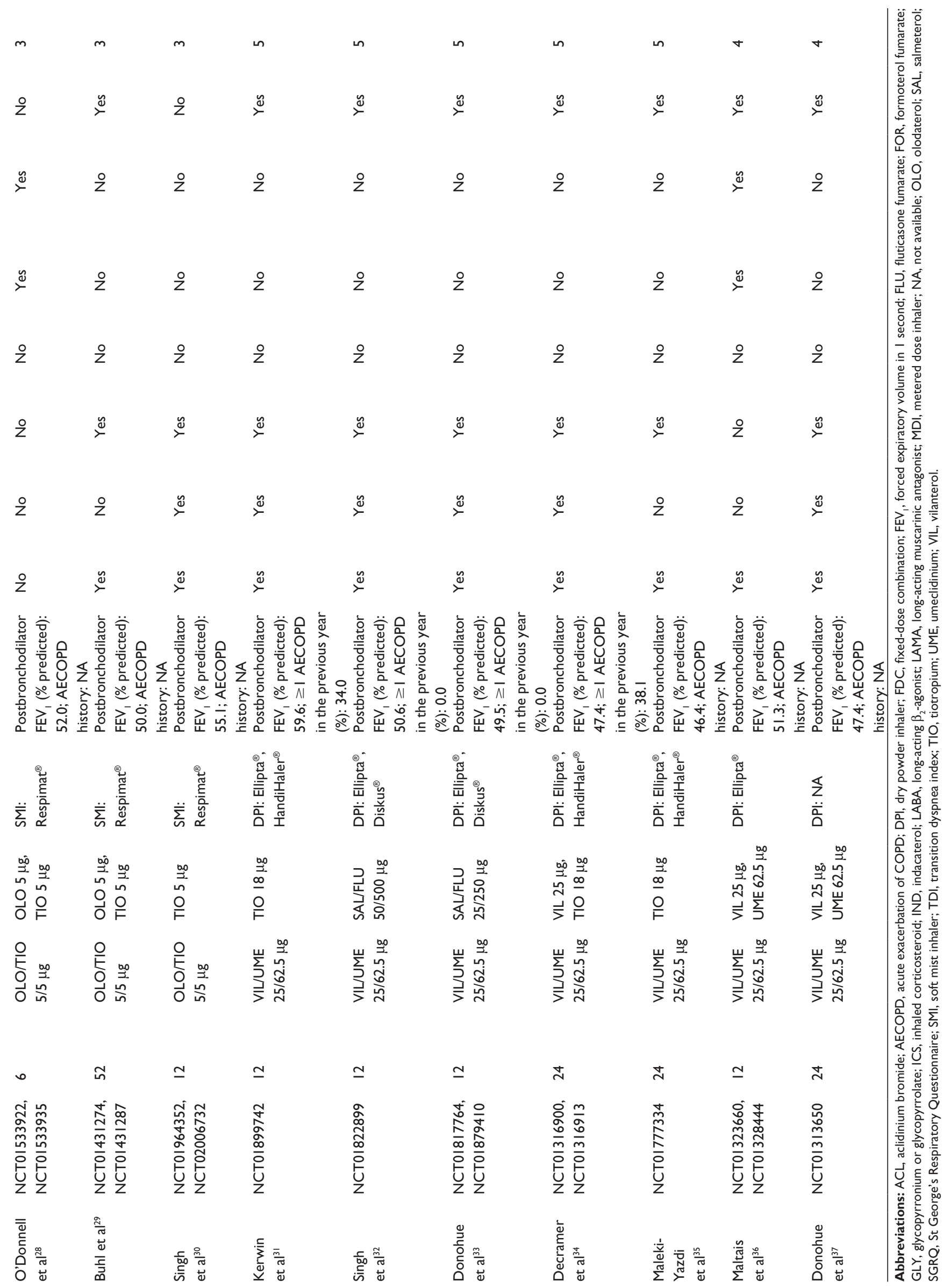




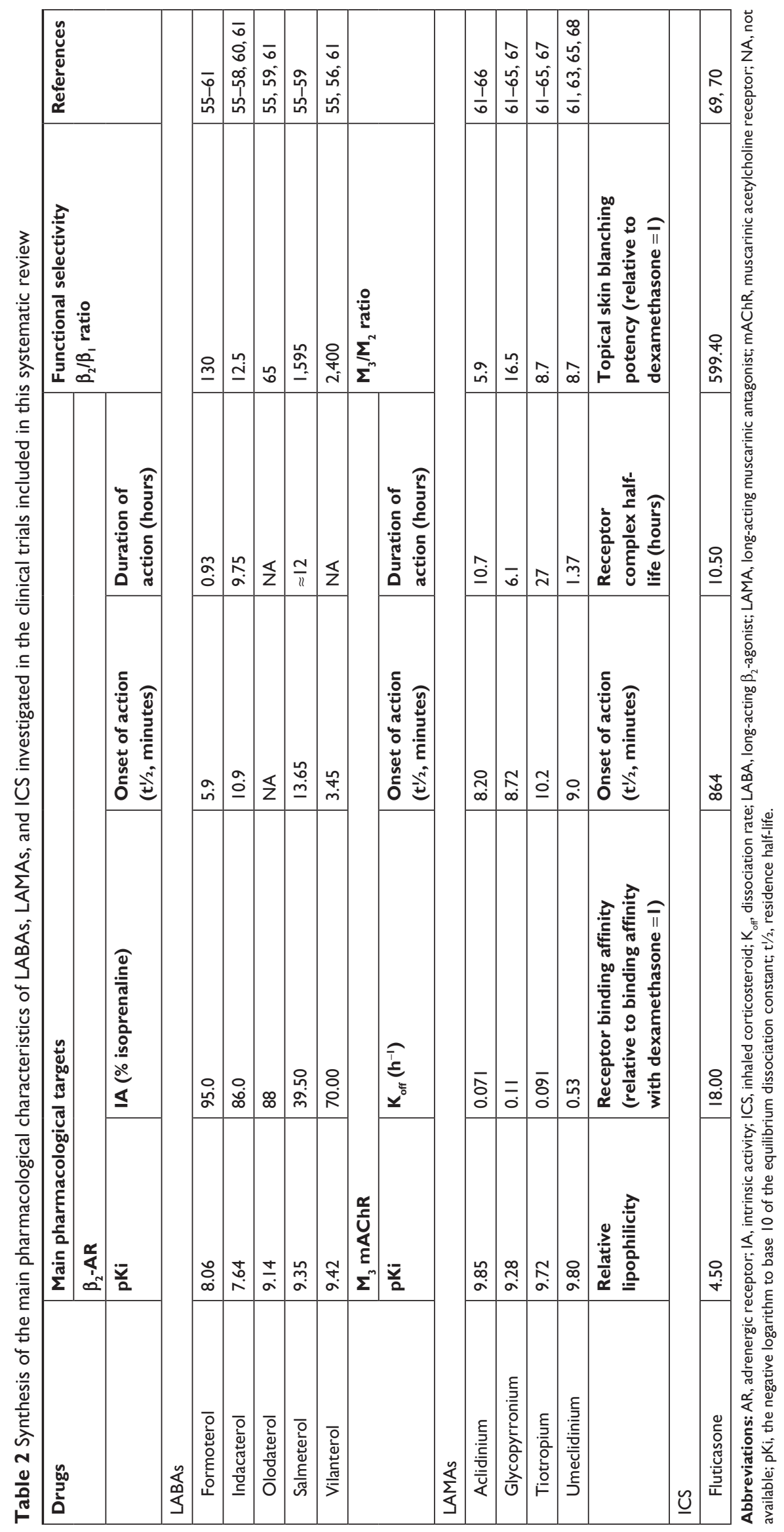




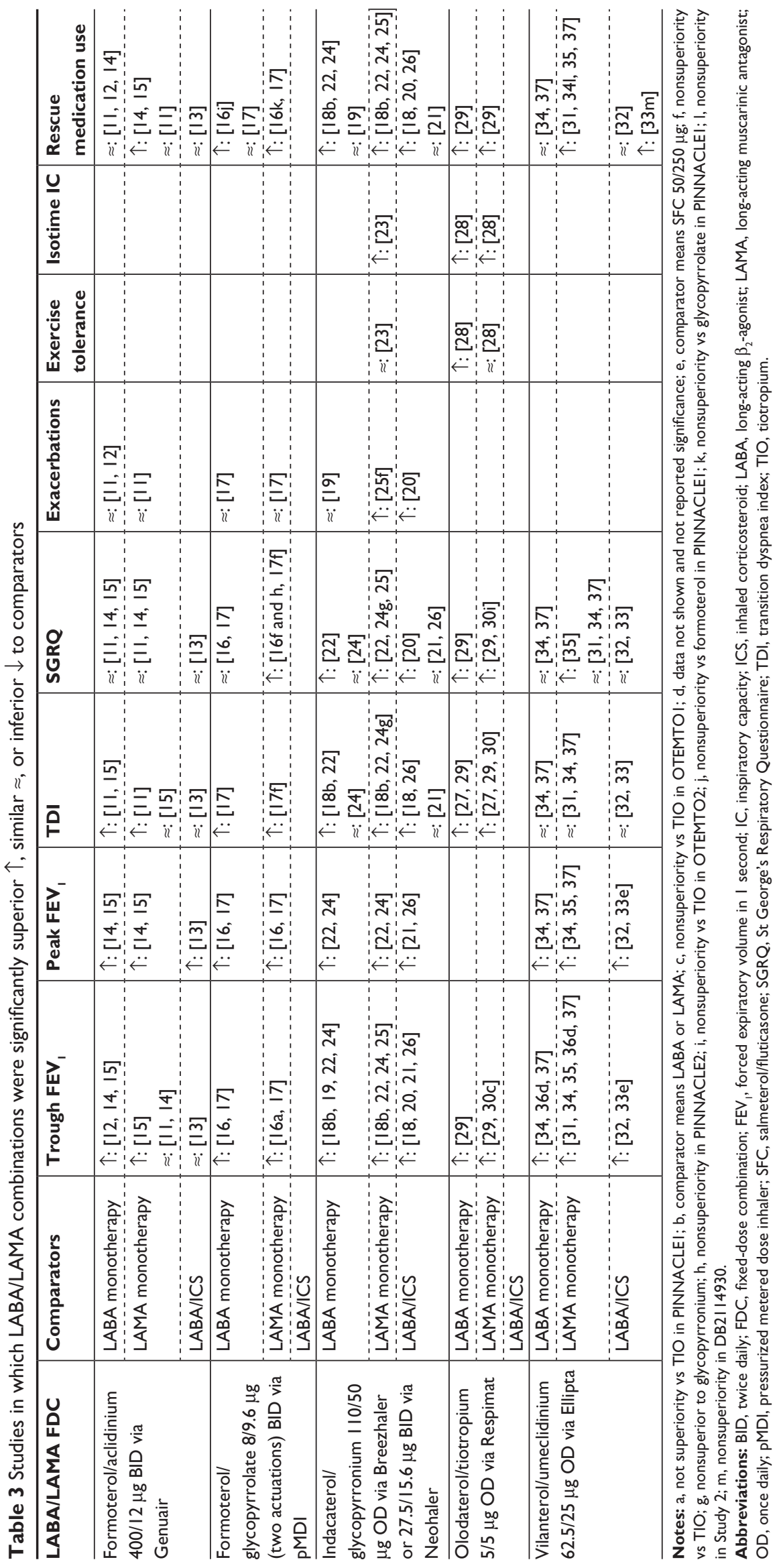




\section{FEV,}

LABA/LAMA FDCs were associated with significant improvements in the morning predose trough $\mathrm{FEV}_{1}$ and peak $\mathrm{FEV}_{1}$ compared with their LABA or LAMA comparators (high quality of evidence, GRADE ++++). These effects were maintained over time.

Formoterol/aclidinium was found superior to formoterol, but not consistently superior to aclidinium in terms of trough $\mathrm{FEV}_{1},{ }^{10,12,14,15}$ whereas the gain in peak $\mathrm{FEV}_{1}$ reached with formoterol/aclidinium was significant vs both formoterol and aclidinium. ${ }^{14,15}$

Formoterol/glycopyrrolate was found superior to both formoterol and glycopyrrolate in improving peak and trough $\mathrm{FEV}_{1} ;{ }^{16,17}$ however, it did not reach superiority vs tiotropium in one study. ${ }^{16}$ Olodaterol/tiotropium was found superior to both olodaterol and tiotropium in improving trough $\mathrm{FEV}_{1} ;{ }^{29,30}$ however, it did not reach superiority vs tiotropium in one study. ${ }^{30}$ No trials reporting superiority of olodaterol/tiotropium for improving peak $\mathrm{FEV}_{1}$ vs LABA or LAMA monotherapy were identified. Both indacaterol/glycopyrronium and vilanterol/umeclidinium have shown superiority vs LABA (indacaterol and vilanterol, respectively) or LAMA (glycopyrronium and tiotropium or umeclidinium and tiotropium, respectively) in terms of improving peak $\mathrm{FEV}_{1}, 22,24,34,35,37$ as well as improving trough $\mathrm{FEV}_{1} \cdot{ }^{18,19,22,24,25,31,34-37}$

LABA/LAMA FDCs also showed significant superiority in improving trough $\mathrm{FEV}_{1}$ and peak $\mathrm{FEV}_{1}$ vs the LABA/ICS comparator salmeterol/fluticasone (SFC; moderate quality of evidence, GRADE +++). One trial demonstrated the superiority of formoterol/aclidinium to SFC 50/500 $\mu \mathrm{g}$ at improving peak $\mathrm{FEV}_{1}$; however, superiority in morning predose $\mathrm{FEV}_{1}$ was not reached. ${ }^{13}$ Four trials showed superiority of indacaterol/glycopyrronium vs SFC FDC at improving trough $\mathrm{FEV}_{1},{ }^{18,20,21,26}$ while two trials demonstrated superiority of indacaterol/glycopyrronium vs the same LABA/ICS at improving peak $\mathrm{FEV}_{1} \cdot{ }^{21,26}$ Two trials comparing vilanterol/ umeclidinium with SFC FDC, although at a lower dose in one study, ${ }^{33}$ demonstrated superiority at improving both trough $\mathrm{FEV}_{1}$ and peak $\mathrm{FEV}_{1} \cdot{ }^{32,33}$

No trials comparing the effects of formoterol/glycopyrrolate or olodaterol/tiotropium with a LABA/ICS on lung function were identified.

\section{TDI}

LABA/LAMA FDCs were also associated with a significant improvement in TDI scores at 12 weeks compared with their LABA or LAMA comparators (high quality of evidence, GRADE ++++$)$.
Formoterol/aclidinium was found to be superior to both formoterol ${ }^{11,15}$ and aclidinium in one study ${ }^{11}$ at improving TDI scores from baseline; however, it did not reach superiority vs aclidinium in one study. ${ }^{14}$ Formoterol/glycopyrrolate also demonstrated superiority at improving TDI scores from baseline vs formoterol or glycopyrrolate in one trial, but it was not superior to tiotropium in the same study. ${ }^{17}$ Olodaterol/tiotropium was found to be superior to olodaterol ${ }^{27,29}$ or tiotropium,,$^{27,29,30}$ and indacaterol/glycopyrronium was found to be superior to indacaterol ${ }^{18,22}$ (except in one study ${ }^{23}$ ) or LAMAs (glycopyrronium or tiotropium). ${ }^{18,22,24}$ It must be noted that in one trial the LABA and LAMA comparators were combined in a single group. ${ }^{18}$ Vilanterol/umeclidinium has not demonstrated to be superiority to vilanterol or umeclidinium and/or tiotropium at improving TDI scores, even if different trials evaluated this improvement. . $^{31,34,37}$

Compared with an LABA/ICS FDC, LABA/LAMA FDCs have shown significant improvements in TDI at 12 weeks (low quality of evidence, GRADE ++). However, when the LABA/LAMA FDCs were analyzed separately, important differences between the compounds were found. Only indacaterol/glycopyrronium has been shown in two trials, ${ }^{18,26}$ to significantly improve TDI scores (not significantly different in one ${ }^{20}$ vs SFC FDC). Formoterol/ aclidinium $^{13}$ and vilanterol/umeclidinium ${ }^{32,33}$ both failed to demonstrate superiority vs SFC FDC, even when compared with a lower ICS dose in one trial. ${ }^{33}$

No trials comparing the effects of formoterol/glycopyrrolate or olodaterol/tiotropium with a LABA/ICS FDC on TDI scores were identified.

\section{SGRQ}

LABA/LAMA FDCs had significant improvements in SGRQ at 12 weeks compared with their LABA or LAMA comparators (moderate quality of evidence, GRADE +++ ).

Formoterol/glycopyrrolate was found to be superior at improving SGRQ scores to glycopyrrolate monotherapy in two trials but was not superior to tiotropium and to formoterol monotherapy in the same studies. ${ }^{16,17}$ Olodaterol/tiotropium was found to be superior to both olodaterol ${ }^{29}$ and tiotropium ${ }^{29,30}$ at improving SGRQ scores. Indacaterol/glycopyrronium was found to be superior to indacaterol ${ }^{22}$ or glycopyrronium and/or tiotropium $^{22,24,25}$ at improving SGRQ scores, while vilanterol/ umeclidinium was found to be superior to umeclidinium in one study ${ }^{35}$ (similar to umeclidinium or tiotropium in three studies, ${ }^{30,33,36}$ but not superior to vilanterol). ${ }^{33,36}$ Formoterol/ aclidinium did not demonstrate superiority vs formoterol or aclidinium at improving SGRQ vs baseline. ${ }^{10,13,14}$ 
Concerning LABA/LAMA FDCs' impact on SGRQ compared with the LABA/ICS comparator, only indacaterol/ glycopyrronium, in one trial, has demonstrated superiority to $\mathrm{SFC} \mathrm{FDC}{ }^{20}$ (not significantly superior in two studies). ${ }^{20,25}$ No trials comparing the effects of formoterol/glycopyrrolate or olodaterol/tiotropium with an LABA/ICS FDC on SGRQ scores were identified. Formoterol/aclidinium ${ }^{13}$ and vilanterol/umeclidinium ${ }^{32,33}$ vs SFC FDC failed to demonstrate superiority, even when compared with a lower ICS dose in one trial. ${ }^{33}$

\section{COPD exacerbations}

LABA/LAMA FDCs have shown significant improvements in the rate of moderate/severe COPD exacerbations over 52 weeks compared with LAMA or LABA/ICS FDC (very low quality of evidence, GRADE +). However, of the LABA/LAMA FDCs, only indacaterol/glycopyrronium has demonstrated superiority to both an LAMA (glycopyrronium, not statistically different vs tiotropium $)^{25}$ and LABA/ ICS FDC $(\mathrm{SFC})^{20}$ in the reduction of exacerbation rates. No trials comparing the effects of formoterol/aclidinium, vilanterol/umeclidinium, formoterol/glycopyrrolate, or olodaterol/tiotropium with any of the LABA, LAMA, or LABA/ICS FDC on moderate/severe exacerbation rates were identified.

\section{Exercise tolerance and IC}

Olodaterol/tiotropium has demonstrated superiority to olodaterol or tiotropium monotherapy at improving isotime IC and superiority to olodaterol monotherapy at improving $\mathrm{ET},{ }^{28}$ while indacaterol/glycopyrronium significantly improved isotime IC vs tiotropium ${ }^{23}$ (moderate quality of evidence, GRADE +++). No published trials comparing the effects of formoterol/aclidinium, vilanterol/umeclidinium, or formoterol/glycopyrrolate with any of the LABA, LAMA, or LABA/ICS FDCs on ET or IC were identified.

\section{Rescue medication use}

LABA/LAMA FDCs showed significant improvements on the use of rescue medication over 12 weeks compared with LABA or LAMA (high quality of evidence, GRADE ++++).

Formoterol/glycopyrrolate was superior to formoterol ${ }^{16}$ (but not superior in one study) ${ }^{16}$ or glycopyrrolate and/or tiotropium, ${ }^{16,17}$ indacaterol/glycopyrronium was superior to indacaterol ${ }^{18,22,24}$ (not significantly different in one study) ${ }^{18}$ as well as to glycopyrronium and/or tiotropium, ${ }^{18,22,24,25}$ and olodaterol/tiotropium was superior to olodaterol ${ }^{29}$ or tiotropium ${ }^{29}$ at reducing the need for rescue medications at 12 weeks. Formoterol/aclidinium was superior to aclidinium in two studies,,${ }^{13,14}$ but not in another one,${ }^{10}$ nor was superior to formoterol at improving rescue medication use. ${ }^{14,15}$ Similarly, vilanterol/umeclidinium was superior to tiotropium and/or umeclidinium, but not superior to vilanterol at improving rescue medication use. ${ }^{31,34,35,37}$

Compared with LABA/ICS FDCs, LABA/LAMA FDCs significantly improved rescue medication use at 12 weeks overall; however, differences between LABA/LAMA FDCs compounds were found (low quality of evidence, GRADE ++). Only indacaterol/glycopyrronium in three studies $^{18,20,26}$ (not in one) $)^{20}$ and vilanterol/umeclidinium in one study ${ }^{32}$ demonstrated superiority vs SFC FDC (not in another study) ${ }^{31}$ at improving rescue medication use (it must be noted that in one trial the dose of SFC was 50/250). ${ }^{33}$ One trial comparing formoterol/aclidinium with an $\mathrm{SFC} \mathrm{FDC}^{13}$ did not find any significant improvements in rescue medication use at 12 weeks. No studies comparing the effects of formoterol/glycopyrrolate or olodaterol/tiotropium with an LABA/ICS FDC on rescue medication use were identified.

\section{Safety}

LABA/LAMA FDCs are a safe therapeutic approach in patients with COPD. Current literature shows that combining an LABA with an LAMA does not increase the risk of AEs or serious AEs (SAEs) compared with their individual components. ${ }^{5,38}$ Furthermore, LABA/LAMA FDCs have been shown to have a comparable safety profile to LABA/ ICS FDCs. ${ }^{5}$

LABA/LAMA FDCs also do not significantly increase the risk of cardiovascular SAEs compared with their individual components. ${ }^{9}$ Intriguingly, some of the LABA/LAMA FDCs showed a numerical trend in protecting against cardiovascular SAEs, whereas other combinations showed a signal in increasing the risk of cardiovascular SAEs. ${ }^{9}$ The frequencies of SAEs and deaths in RCTs of LABA/LAMA FDCs are low. However, while COPD makes it difficult to perform studies that are adequately powered to detect the real safety profile of LABA/LAMA FDCs, it appears that the cardiac safety of LAMA/LABA FDCs could be lower in COPD patients who have concomitant cardiovascular diseases, prolonged corrected QT interval, or polypharmacy. ${ }^{39}$

In any case, we have to highlight that the occurrence of rare/uncommon SAEs may be related to several individual patient characteristics and that COPD patients with comorbidities are usually excluded from RCTs. In fact, a recent observational study of a cohort of 31,138 patients with COPD 
who added an LAMA to an LABA, or vice versa, indicated that adding a second long-acting bronchodilator does not increase the risk of most cardiovascular events in the realworld-setting treatment of COPD. However, the authors detected a modest, although significant, increase in the risk of heart failure. ${ }^{40}$ To confirm these data from meta-analyses and observational studies, high-quality, large, RCTs including patients with COPD and cardiovascular comorbidities are warranted. ${ }^{39}$

Moreover, also the drug formulations and the characteristics of the specific devices may modulate the frequency of SAEs and lead to potential imbalance of the safety profile in favor of some LABA/LAMA FDCs rather than others. ${ }^{41,42}$ In fact, while some inhaler devices deliver fine particles leading to increased lung deposition, others deliver greater particles that induce oropharyngeal deposition of drugs. The latter condition may result in a greater systemic absorption of bronchodilators, with a potential increased risk of AEs. ${ }^{41,42}$

\section{Discussion}

The main aim of this systematic review was to investigate whether the evidence for the efficacy and safety of all marketed LABA/LAMA FDCs or those under development is comparable, in terms of the number of RCTs and outcomes. We found that evidence supporting the use of different LABA/LAMA FDCs for the management of COPD is heterogeneous.

In the era of evidence-based medicine, we rely on the literature to identify the best approach to treat patients, and systematic reviews are a valuable tool to define a clear picture of current literature on LABA/LAMA FDCs. Several systematic reviews and meta-analyses have been conducted and published regarding the effect of the LABA/LAMA class on different outcomes such as changes in $\mathrm{FEV}_{1}$, patientreported outcomes, and safety, ${ }^{5,9,43,44}$ but none of them was focused on producing a tool to easily identify which (if not all) LABA/LAMA FDCs have demonstrated superior results when compared with single bronchodilators (LABA or LAMA) or LABA/ICS. If the goal of treatment is, eg, to reduce dyspnea, using the results of this systematic review, we can now choose which FDC has shown to improve this outcome; again, if the focus is to reduce exacerbations, we can easily find the right answer to this question in the results of this review.

Overall, LABA/LAMA FDCs have shown superiority regarding lung function improvement vs comparators. However, at difference with others, indacaterol/glycopyrronium and vilanterol/umeclidinium were the only FDCs demonstrating statistical superiority vs LABA and LAMA monotherapies and LABA/ICS in terms of improvements in trough $\mathrm{FEV}_{1}$, which is the most commonly investigated (and requested by health authorities) outcome in studies on COPD.

Regarding TDI improvement, indacaterol/glycopyrronium has shown superior results vs each comparator, but surprisingly vilanterol/umeclidinium did not show any superiority vs LABA or LAMA or LABA/ICS FDCs, even if many trials evaluated this outcome. Similarly, significant improvements in SGRQ scores were only demonstrated with indacaterol/glycopyrronium, while other LABA/LAMA FDCs (particularly formoterol/aclidinium and vilanterol/ umeclidinium) showed no advantage over LABA, LAMA, or LABA/ICS FDCs.

One of the biggest differences between the different LABA/LAMA FDCs is their effect on COPD exacerbation rates, with only indacaterol/glycopyrronium demonstrating superiority at improving COPD exacerbation rates vs LAMA or LABA/ICS FDCs. One Cochrane review found a significant heterogeneity analyzing this outcome for different LABA/LAMA FDCs and concluded that it is still not clear whether only indacaterol/glycopyrronium prevents COPD exacerbations or all LABA/LAMA FDCs are able to prevent these events. ${ }^{45}$ In our opinion, studies investigating the superiority of LABA/LAMA FDCs at preventing COPD exacerbations vs LABA monotherapy are not needed as it is already proven that $\mathrm{LAMAs}^{46,47}$ and LABA/ICS FDCs ${ }^{48}$ are superior to LABAs for this outcome. As indacaterol/glycopyrronium demonstrated better exacerbation prevention vs both LAMA (glycopyrronium) and LABA/ICS (SFC), the demonstration of superiority vs any LABA seems to be irrelevant.

Regarding exercise tolerance and isotime IC, more data supporting LABA/LAMA FDCs are needed as this is an important outcome impacting the quality of life of COPD patients. Olodaterol/tiotropium has shown superiority vs LABA regarding isotime IC and ET, while indacaterol/ glycopyrronium was superior to LAMA regarding isotime IC. Actually, a pairwise and network meta-analysis conducted by Calzetta et al documented that LABA/LAMA combination was superior to the monocomponents in increasing both ET and IC, providing support to the double bronchodilation strategy for the increase of exercise tolerance in COPD patients. ${ }^{43}$ One suggestion for future trials is to combine double bronchodilation and exercise training; this could bring superior results in terms of ET. Actually, as shown by Ofir et $\mathrm{al}^{49} \mathrm{COPD}$ patients often stop exercise for leg discomfort, so optimizing bronchodilation with an LABA/LAMA FDC 
may result in prolonging exercise duration or shifting the locus of symptom limitation from dyspnea to leg fatigue. As such, combining exercise training (to improve limb muscle fatigue) with double bronchodilation may produce superior results in terms of exercise tolerance for COPD patients.

We were able to detect some differences between different LABA/LAMA FDCs; in fact, some LABA/LAMA FDCs showed significant benefits on specific outcomes, but several inconsistencies in the evidence supporting the efficacy of LABA/LAMA FDCs were found; these were likely caused by differences in study design, comparators, outcomes, and patient populations or by differences existing between the LABA/LAMA FDCs. Being aware of these differences allows us to choose the FDC that has been shown to improve a specific outcome that appears to be critical in a given patient.

The 2018 GOLD Report recommends the use of two bronchodilators for Group B patients with persistent breathlessness on monotherapy and Group C patients with persistent exacerbations, and indicates LABA/LAMA combinations as preferred treatment in Groups D patients. ${ }^{50}$ The present systematic review supports the GOLD algorithm, as LABA/LAMA FDCs have shown superiority vs any comparators for the vast majority of evaluated outcomes; yet, the step-up strategy recommended by the GOLD report is supported by this systematic review for the same reason. The superiority shown by some LABA/LAMA FDCs vs LABA/ICSs for the majority of evaluated outcomes is supporting the GOLD 2018 report, as current evidence is in favor of the double bronchodilation strategy for both efficacy and safety reasons. As acknowledged by the GOLD committee, long-term treatment with ICS (especially fluticasone) could be associated with the risk of pneumonia and other adverse effects. Therefore, LABA/LAMA seems an overall safer and more effective option for COPD patient management.

Potentially an early start with a fast-acting LABA/LAMA FDC at the time of COPD diagnosis could lead to rapid improvements in symptoms. Prompt symptom relief will give reassurance of effectiveness and could be a key factor in patient compliance, thus likely improving adherence to the prescribed medications that are usually very low in COPD patients, with a negative influence on outcomes. This approach is supported by the GOLD 2018 report that states that, for patients with severe breathlessness, initial therapy with two bronchodilators may be considered. ${ }^{50}$

The focus of this study was to compare the LABA/LAMA FDC in COPD patients, and the results must be interpreted in the light of the population enrolled in these trials. Of course, in asthmatic and ACO patients, an accurate evaluation of an ICS-containing regimen is mandatory.

From a safety standpoint, the current evidence suggests that LABA/LAMA FDCs are a safe therapeutic approach in COPD patients. While the choice of a specific LAMA/ LABA FDC should not be based on the specific safety profile, postmarketing surveillance and observational studies are welcomed to adequately clarify the safety of any LABA/LAMA FDC in daily clinical practice. A recent study on 284,220 LABA-LAMA-naïve patients with COPD has shown an increased risk of a severe cardiovascular disease event within 30 days of initiation of LABA or LAMA therapy. ${ }^{51}$ However, the risk was reduced in the longer term. Therefore, this study highlights the importance of a careful early management of COPD after the introduction of LABA or LAMA therapy.

We did not perform any meta-analysis to compare the different LABA/LAMA FDCs as it was not the objective of the study. In our opinion, a statistically significant difference vs comparators could help to establish the superiority of one treatment over another, given the lack of universally accepted clinically relevant differences between active treatments. However, it must be pointed out that statistically significant superiority does not always mean difference in clinical relevance.

Finally, although no further studies could formally be considered in this systematic review as the methodological criteria already registered in PROSPERO (CRD42017070930) set the literature search at the end of September 2017, we cannot overlook recent RCTs on triple FDC therapy including an ICS plus an LABA plus an LAMA, such as the TRIBUTE and IMPACT studies, ${ }^{52,53}$ which provided relevant findings concerning the efficacy and safety of adding an ICS to the double bronchodilation therapy in the management of COPD patients. Interestingly, the triple therapy demonstrated a greater protective effect against COPD exacerbations in patients with higher blood eosinophil levels, as further confirmed by the SUNSET study ${ }^{54}$ that aimed to evaluate the impact of de-escalation from the long-term triple therapy to indacaterol/glycopyrronium in nonfrequently exacerbating COPD patients.

\section{Conclusion}

Evidence supporting the efficacy of different LABA/LAMA FDCs and their clinical relevance for the management of COPD are heterogeneous across the literature, particularly for improvements in TDI and SGRQ scores, and even more for exacerbation prevention, and changes in ET and IC. Furthermore, not all LABA/LAMA FDCs have shown 
superiority over LABA/ICS for most of the evaluated outcomes. Based on the published evidence, the equivalence of all LABA/LAMA FDCs cannot be established. Indacaterol/ glycopyrronium is so far the LABA/LAMA combination supported by the more robust evidence of superiority vs LABA, LAMA, and LABA/ICS across the evaluated outcomes.

\section{Acknowledgments}

We would like to thank Simone Boniface of Springer Healthcare Communications who edited the manuscript before submission. This medical writing support was funded by Novartis Farma, Italy. This study and the article-processing charges were supported by an unrestricted grant from Novartis Farma, which was not responsible for the study, data analysis, data interpretation, and manuscript writing.

\section{Author contributions}

All authors provided substantial contributions to conception and design, acquisition of data, and analysis and interpretation of data; drafted the article; and agreed to be accountable for all aspects of the work in ensuring that questions related to the accuracy or integrity of any part of the work are appropriately investigated and resolved. All the authors revised the manuscript critically for important intellectual content and approved the version to be published.

\section{Disclosure}

PR has participated as a lecturer, speaker, and/or advisor in scientific meetings and courses under the sponsorship of Almirall, AstraZeneca, Biofutura, Boehringer Ingelheim, Chiesi Farmaceutici, GlaxoSmithKline, Menarini Group, Mundipharma, and Novartis. Her department has been funded by Almirall, Boehringer Ingelheim, Novartis, and Zambon. LC has participated as advisor in scientific meetings under the sponsorship of Boehringer Ingelheim and Novartis, received non-financial support by AstraZeneca, received a research grant partially funded by Almirall, Boehringer Ingelheim, and Novartis, and has been a consultant to Edmond Pharma, Verona Pharma, and Zambon. His department has been funded by Almirall, Boehringer Ingelheim, Novartis, and Zambon. FB has participated as a lecturer, speaker, and/or advisor in scientific meetings and courses under the sponsorship of AstraZeneca, Biofutura, Boehringer Ingelheim, Chiesi Farmaceutici, Dompè, GlaxoSmithKline, Lallemand Pharma, Malesci/Guidotti, Menarini Group, Mundipharma, Novartis, Teva, and Zambon. EC has participated as a lecturer, speaker, and/or advisor in scientific meetings and courses under the sponsorship of AstraZeneca, Boehringer Ingelheim, Guidotti/Malesci, Linde, Menarini Group, and Novartis, and has received financial support for research and for congress attendance from Boehringer Ingelheim, Medical Products Research, and Novartis. GP has participated as a lecturer, speaker, and/or advisor in scientific meetings and courses under the sponsorship of AstraZeneca, Biofutura, Boehringer Ingelheim, Chiesi Farmaceutici, Dompè, GlaxoSmithKline, Malesci/Guidotti, Menarini Group, Mundipharma, Novartis, Teva, and Zambon. AR has participated as a lecturer, speaker, and/or advisor in scientific meetings and courses under the sponsorship of AstraZeneca, Biofutura, Boehringer Ingelheim, Chiesi Farmaceutici, Menarini Group, and Novartis. NS has participated as a lecturer, speaker, and/or advisor in scientific meetings and courses under the sponsorship of AstraZeneca, Boehringer Ingelheim, Chiesi Farmaceutici, Guidotti/Malesci, Menarini Group, Mundipharma, Teva, and Zambon, and has received financial support for research and for congress attendance from AstraZeneca, Boehringer Ingelheim, Chiesi Farmaceutici, Guidotti/Malesci, and Novartis. FDM has participated as a lecturer, speaker, and/or advisor in scientific meetings and courses under the sponsorship of Almirall, AstraZeneca, Boehringer Ingelheim, Chiesi Farmaceutici, Dompè, Guidotti/Malesci, GlaxoSmithKline, Menarini Group, Novartis, and Zambon, and has received financial support for research from Novartis. MC has participated as a lecturer, speaker, and/or advisor in scientific meetings and courses under the sponsorship of Almirall, AstraZeneca, Biofutura, Boehringer Ingelheim, Chiesi Farmaceutici, Dey, GlaxoSmithKline, Kamada, Lallemand Pharma, Menarini Group, Mundipharma, Novartis, Ockham Biotech, Pfizer, Skyepharma, Stallergenes, Teva, Verona Pharma, and Zambon. The authors report no other conflicts of interest in this work.

\section{References}

1. World Health Organization [homepage on the Internet]. Chronic Respiratory Diseases: Burden of COPD. Geneva: World Health Organization; 2017. Available from: http://www.who.int/respiratory/copd/burden/en/. Accessed November 3, 2017.

2. Global Initiative for Chronic Obstructive Lung Disease [homepage on the Internet]. Global strategy for the diagnosis, management, and prevention of chronic obstructive pulmonary disease; [updated 2017]. Available from: www.goldcopd.org/. Accessed December 2016.

3. Calzetta L, Matera MG, Cazzola M. Pharmacological interaction between LABAs and LAMAs in the airways: optimizing synergy. Eur J Pharmacol. 2015;761:168-173.

4. Cazzola M, Calzetta L, Ora J, Puxeddu E, Rogliani P, Matera MG. Searching for the synergistic effect between aclidinium and formoterol: from bench to bedside. Respir Med. 2015;109(10):1305-1311.

5. Rodrigo GJ, Price D, Anzueto A, et al. LABA/LAMA combinations versus LAMA monotherapy or LABA/ICS in COPD: a systematic review and meta-analysis. Int J Chron Obstruct Pulmon Dis. 2017;12:907-922.

6. Rogliani P, Calzetta L, Coppola A, et al. Optimizing drug delivery in COPD: the role of inhaler devices. Respir Med. 2017;124:6-14.

7. Moher D, Liberati A, Tetzlaff J, Altman DG; PRISMA Group. Preferred reporting items for systematic reviews and meta-analyses: the PRISMA Statement. Open Med. 2009;3(3):e123-e130. 
8. Moher D, Shamseer L, Clarke M, et al. Preferred reporting items for systematic review and meta-analysis protocols (PRISMA-P) 2015 statement. Syst Rev. 2015;4:1.

9. Calzetta L, Rogliani P, Matera MG, Cazzola M. A systematic review with meta-analysis of dual bronchodilation with LAMA/LABA for the treatment of stable COPD. Chest. 2016;149(5):1181-1196.

10. Guyatt G, Oxman AD, Akl EA, et al. GRADE guidelines: 1. IntroductionGRADE evidence profiles and summary of findings tables. J Clin Epidemiol. 2011;64(4):383-394.

11. D’Urzo A, Rennard S, Kerwin E, et al. A randomised double-blind, placebo-controlled, long-term extension study of the efficacy, safety and tolerability of fixed-dose combinations of aclidinium/formoterol or monotherapy in the treatment of chronic obstructive pulmonary disease. Respir Med. 2017;125:39-48.

12. Donohue JF, Soong W, Wu X, Shrestha P, Lei A. Long-term safety of aclidinium bromide/formoterol fumarate fixed-dose combination: results of a randomized 1-year trial in patients with COPD. Respir Med. 2016;116:41-48.

13. Vogelmeier C, Paggiaro PL, Dorca J, et al. Efficacy and safety of aclidinium/formoterol versus salmeterol/fluticasone: a phase $3 \mathrm{COPD}$ study. Eur Respir J. 2016;48(4):1030-1039.

14. Singh D, Jones PW, Bateman ED, et al. Efficacy and safety of aclidinium bromide/formoterol fumarate fixed-dose combinations compared with individual components and placebo in patients with COPD (ACLIFORM-COPD): a multicentre, randomised study. BMC Pulm Med. 2014;14:178.

15. D'Urzo AD, Rennard SI, Kerwin EM, et al. Efficacy and safety of fixed-dose combinations of aclidinium bromide/formoterol fumarate: the 24-week, randomized, placebo-controlled AUGMENT COPD study. Respir Res. 2014;15:123.

16. Martinez FJ, Rabe KF, Ferguson GT, et al. Efficacy and safety of glycopyrrolate/formoterol metered dose inhaler formulated using cosuspension delivery technology in patients with COPD. Chest. 2017; 151(2):340-357.

17. Hanania NA, Tashkin DP, Kerwin EM, et al. Long-term safety and efficacy of glycopyrrolate/formoterol metered dose inhaler using novel Co-Suspension ${ }^{\mathrm{TM}}$ Delivery Technology in patients with chronic obstructive pulmonary disease. Respir Med. 2017;126: $105-115$.

18. Vogelmeier CF, Gaga M, Aalamian-Mattheis M, et al. Efficacy and safety of direct switch to indacaterol/glycopyrronium in patients with moderate COPD: the CRYSTAL open-label randomised trial. Respir Res. 2017;18(1):140.

19. Ferguson GT, Taylor AF, Thach C, et al. Long-term maintenance bronchodilation with indacaterol/glycopyrrolate versus indacaterol in moderate-to-severe COPD patients: the FLIGHT 3 Study. Chronic Obstr Pulm Dis. 2016;3(4):716-728.

20. Wedzicha JA, Banerji D, Chapman KR, et al. Indacaterol-Glycopyrronium versus Salmeterol-Fluticasone for COPD. N Engl J Med. 2016;374(23): 2222-2234.

21. Zhong N, Wang C, Zhou X, et al. LANTERN: a randomized study of QVA149 versus salmeterol/fluticasone combination in patients with COPD. Int J Chron Obstruct Pulmon Dis. 2015;10:1015-1026.

22. Mahler DA, Kerwin E, Ayers RT, et al. FLIGHT: efficacy and safety of QVA149 (indacaterol/glycopyrrolate) versus its monocomponents and placebo in patients with COPD. Am J Respir Crit Care Med. 2015; 192(9):1068-1079.

23. Beeh KM, Korn S, Beier J, et al. Effect of QVA149 on lung volumes and exercise tolerance in COPD patients: the BRIGHT study. Respir Med. 2014;108(4):584-592.

24. Bateman ED, Ferguson GT, Barnes N, et al. Dual bronchodilation with QVA149 versus single bronchodilator therapy: the SHINE study. Eur Respir J. 2013;42(6):1484-1494.

25. Wedzicha JA, Decramer M, Ficker JH, et al. Analysis of chronic obstructive pulmonary disease exacerbations with the dual bronchodilator QVA149 compared with glycopyrronium and tiotropium (SPARK): a randomised, double-blind, parallel-group study. Lancet Respir Med. 2013;1(3):199-209.
26. Vogelmeier CF, Bateman ED, Pallante J, et al. Efficacy and safety of once-daily QVA149 compared with twice-daily salmeterol-fluticasone in patients with chronic obstructive pulmonary disease (ILLUMINATE): a randomised, double-blind, parallel group study. Lancet Respir Med. 2013;1(1):51-60.

27. Ferguson GT, Karpel J, Bennett N, et al. Effect of tiotropium and olodaterol on symptoms and patient-reported outcomes in patients with COPD: results from four randomised, double-blind studies. NPJ Prim Care Respir Med. 2017;27(1):7.

28. O’Donnell DE, Casaburi R, Frith P, et al. Effects of combined tiotropium/olodaterol on inspiratory capacity and exercise endurance in COPD. Eur Respir J. 2017;49(4):pii:1601348.

29. Buhl R, Maltais F, Abrahams R, et al. Tiotropium and olodaterol fixeddose combination versus mono-components in COPD (GOLD 2-4). Eur Respir J. 2015;45(4):969-979.

30. Singh D, Ferguson GT, Bolitschek J, et al. Tiotropium + olodaterol shows clinically meaningful improvements in quality of life. Respir Med. 2015;109(10):1312-1319.

31. Kerwin EM, Kalberg CJ, Galkin DV, et al. Umeclidinium/vilanterol as step-up therapy from tiotropium in patients with moderate COPD: a randomized, parallel-group, 12-week study. Int J Chron Obstruct Pulmon Dis. 2017;12:745-755.

32. Singh D, Worsley S, Zhu CQ, Hardaker L, Church A. Umeclidinium/ vilanterol versus fluticasone propionate/salmeterol in COPD: a randomised trial. BMC Pulm Med. 2015;15:91.

33. Donohue JF, Worsley S, Zhu CQ, Hardaker L, Church A. Improvements in lung function with umeclidinium/vilanterol versus fluticasone propionate/salmeterol in patients with moderate-to-severe COPD and infrequent exacerbations. Respir Med. 2015;109(7): $870-881$.

34. Decramer M, Anzueto A, Kerwin E, et al. Efficacy and safety of umeclidinium plus vilanterol versus tiotropium, vilanterol, or umeclidinium monotherapies over 24 weeks in patients with chronic obstructive pulmonary disease: results from two multicentre, blinded, randomised controlled trials. Lancet Respir Med. 2014;2(6):472-486.

35. Maleki-Yazdi MR, Kaelin T, Richard N, Zvarich M, Church A. Efficacy and safety of umeclidinium/vilanterol $62.5 / 25 \mathrm{mcg}$ and tiotropium $18 \mathrm{mcg}$ in chronic obstructive pulmonary disease: results of a 24-week, randomized, controlled trial. Respir Med. 2014;108(12): 1752-1760.

36. Maltais F, Singh S, Donald AC, et al. Effects of a combination of umeclidinium/vilanterol on exercise endurance in patients with chronic obstructive pulmonary disease: two randomized, double-blind clinical trials. Ther Adv Respir Dis. 2014;8(6):169-181.

37. Donohue JF, Maleki-Yazdi MR, Kilbride S, Mehta R, Kalberg C, Church A. Efficacy and safety of once-daily umeclidinium/vilanterol 62.5/25 mcg in COPD. Respir Med. 2013;107(10):1538-1546.

38. Oba Y, Sarva ST, Dias S. Efficacy and safety of long-acting $\beta$-agonist/ long-acting muscarinic antagonist combinations in COPD: a network meta-analysis. Thorax. 2016;71(1):15-25.

39. Lahousse L, Verhamme KM, Stricker BH, Brusselle GG. Cardiac effects of current treatments of chronic obstructive pulmonary disease. Lancet Respir Med. 2016;4(2):149-164.

40. Suissa S, Dell'Aniello S, Ernst P. Concurrent use of long-acting bronchodilators in COPD and the risk of adverse cardiovascular events. Eur Respir J. 2017;49(5):pii:1602245.

41. Cazzola M, Calzetta L, Rogliani P, Matera MG. Tiotropium formulations and safety: a network meta-analysis. Ther Adv Drug Saf. 2017; 8(1):17-30.

42. Rogliani P, Calzetta L, Coppola A, et al. Optimizing drug delivery in COPD: the role of inhaler devices. Respir Med. 2017;124:6-14.

43. Calzetta L, Rogliani P, Ora J, Puxeddu E, Cazzola M, Matera MG LABA/LAMA combination in COPD: a meta-analysis on the duration of treatment. Eur Respir Rev. 2017;26(143):pii:160043.

44. Price D, Østrem A, Thomas M, Welte T. Dual bronchodilation in COPD: lung function and patient-reported outcomes - a review. Int J Chron Obstruct Pulmon Dis. 2017;12:141-168. 
45. Horita N, Goto A, Shibata Y, et al. Long-acting muscarinic antagonist (LAMA) plus long-acting beta-agonist (LABA) versus LABA plus inhaled corticosteroid (ICS) for stable chronic obstructive pulmonary disease (COPD). Cochrane Database Syst Rev. 2017;2: CD012066.

46. Decramer ML, Chapman KR, Dahl R, et al. Once-daily indacaterol versus tiotropium for patients with severe chronic obstructive pulmonary disease (INVIGORATE): a randomised, blinded, parallel-group study. Lancet Respir Med. 2013;1(7):524-533.

47. Vogelmeier C, Hederer B, Glaab T, et al. Tiotropium versus salmeterol for the prevention of exacerbations of COPD. $N$ Engl J Med. 2011; 364(12):1093-1103.

48. Calverley PM, Anderson JA, Celli B, et al. Salmeterol and fluticasone propionate and survival in chronic obstructive pulmonary disease. N Engl J Med. 2007;356(8):775-789.

49. Ofir D, Laveneziana P, Webb KA, Lam YM, O’Donnell DE. Mechanisms of dyspnea during cycle exercise in symptomatic patients with GOLD stage I chronic obstructive pulmonary disease. Am J Respir Crit Care Med. 2008;177(6):622-629.

50. Global Initiative for Chronic Obstructive Lung Disease [homepage on the Internet]. Global strategy for the diagnosis, management, and prevention of chronic obstructive pulmonary disease; [updated 2018]. Available from: www.goldcopd.org/. Accessed December 2017.

51. Wang MT, Liou JT, Lin CW, et al. Association of cardiovascular risk with inhaled long-acting bronchodilators in patients with chronic obstructive pulmonary disease: a nested case-control study. JAMA Intern Med. 2018;178(2):229-238.

52. Papi A, Vestbo J, Fabbri L, et al. Extrafine inhaled triple therapy versus dual bronchodilator therapy in chronic obstructive pulmonary disease (TRIBUTE): a double-blind, parallel group, randomised controlled trial. Lancet. 2018;391(10125):1076-1084.

53. Lipson DA, Barnhart F, Brealey N, et al. Once-daily single-inhaler triple versus dual therapy in patients with COPD. N Engl J Med. 2018; 378(18):1671-1680.

54. Chapman KR, Hurst JR, Frent SM, et al. Long-term triple therapy deescalation to indacaterol/glycopyrronium in COPD patients (SUNSET): a randomized, double-blind, triple-dummy clinical trial. Am J Respir Crit Care Med. 2018;198(3):329-339.

55. Cazzola M, Page CP, Rogliani P, Matera MG. $\beta_{2}$-agonist therapy in lung disease. Am J Respir Crit Care Med. 2013;187(7):690-696.

56. Slack RJ, Barrett VJ, Morrison VS, et al. In vitro pharmacological characterization of vilanterol, a novel long-acting $\beta_{2}$-adrenoceptor agonist with 24-hour duration of action. J Pharmacol Exp Ther. 2013;344(1): 218-230.

57. Battram C, Charlton SJ, Cuenoud B, et al. In vitro and in vivo pharmacological characterization of 5-[(R)-2-(5,6-diethyl-indan-2-ylamino)1-hydroxy-ethyl]-8-hydroxy-1H-quinolin-2-one (indacaterol), a novel inhaled beta(2) adrenoceptor agonist with a 24-h duration of action. $J$ Pharmacol Exp Ther. 2006;317(2):762-770.

58. Aparici M, Gómez-Angelats M, Vilella D, et al. Pharmacological characterization of abediterol, a novel inhaled $\beta(2)$-adrenoceptor agonist with long duration of action and a favorable safety profile in preclinical models. J Pharmacol Exp Ther. 2012;342(2):497-509.
59. Bouyssou T, Casarosa P, Naline E, et al. Pharmacological characterization of olodaterol, a novel inhaled beta2-adrenoceptor agonist exerting a 24-hour-long duration of action in preclinical models. J Pharmacol Exp Ther. 2010;334(1):53-62.

60. Naline E, Trifilieff A, Fairhurst RA, Advenier C, Molimard M. Effect of indacaterol, a novel long-acting beta2-agonist, on isolated human bronchi. Eur Respir J. 2007;29(3):575-581.

61. Calzetta L, Matera MG, Cazzola M. Pharmacological mechanisms leading to synergy in fixed-dose dual bronchodilator therapy. Curr Opin Pharmacol. 2018;40:95-103.

62. Casarosa P, Bouyssou T, Germeyer S, Schnapp A, Gantner F, Pieper M. Preclinical evaluation of long-acting muscarinic antagonists: comparison of tiotropium and investigational drugs. J Pharmacol Exp Ther. 2009;330(2):660-668.

63. Cazzola M, Beeh KM, Price D, Roche N. Assessing the clinical value of fast onset and sustained duration of action of long-acting bronchodilators for COPD. Pulm Pharmacol Ther. 2015;31:68-78.

64. Rogliani P, Calzetta L, Ora J, et al. Pharmacological assessment of the onset of action of aclidinium and glycopyrronium versus tiotropium in COPD patients and human isolated bronchi. Eur J Pharmacol. 2015; 761:383-390.

65. Naline E, Grassin Delyle S, Salvator H, et al. Comparison of the in vitro pharmacological profiles of long-acting muscarinic antagonists in human bronchus. Pulm Pharmacol Ther. 2018;49:46-53.

66. Gavaldà A, Ramos I, Carcasona $\mathrm{C}$, et al. The in vitro and in vivo profile of aclidinium bromide in comparison with glycopyrronium bromide. Pulm Pharmacol Ther. 2014;28(2):114-121.

67. Villetti G, Pastore F, Bergamaschi M, et al. Bronchodilator activity of (3R)-3-[[[(3-fluorophenyl)[(3,4,5-trifluorophenyl)methyl]amino] carbonyl]oxy]-1-[2-oxo-2-(2-thienyl)ethyl]-1-azoniabicyclo[2.2.2] octane bromide (CHF5407), a potent, long-acting, and selective muscarinic M3 receptor antagonist. J Pharmacol Exp Ther. 2010;335(3): 622-635.

68. Salmon M, Luttmann MA, Foley JJ, et al. Pharmacological characterization of GSK573719 (umeclidinium): a novel, long-acting, inhaled antagonist of the muscarinic cholinergic receptors for treatment of pulmonary diseases. J Pharmacol Exp Ther. 2013;345(2):260-270.

69. Staresinic AG, Sorkness CA. Fluticasone propionate: a potent inhaled corticosteroid for the treatment of asthma. Expert Opin Pharmacother. 2000;1(6):1227-1244.

70. Daley-Yates PT, Parkins DA, Thomas MJ, GillettB, House KW, OrtegaHG. Pharmacokinetic, pharmacodynamic, efficacy, and safety data from two randomized, double-blind studies in patients with asthma and an in vitro study comparing two dry-powder inhalers delivering a combination of salmeterol 50 microg and fluticasone propionate 250 microg: implications for establishing bioequivalence of inhaled products. Clin Ther. 2009;31(2):370-385.
International Journal of COPD

\section{Publish your work in this journal}

The International Journal of COPD is an international, peer-reviewed journal of therapeutics and pharmacology focusing on concise rapid reporting of clinical studies and reviews in COPD. Special focus is given to the pathophysiological processes underlying the disease, intervention programs, patient focused education, and self management protocols.
Dovepress

This journal is indexed on PubMed Central, MedLine and CAS. The manuscript management system is completely online and includes a very quick and fair peer-review system, which is all easy to use. Visit http://www.dovepress.com/testimonials.php to read real quotes from published authors. 